Check for updates

Cite this: RSC Adv., 2017, 7, 26849

Received 18th February 2017

Accepted 28th April 2017

DOI: $10.1039 / \mathrm{c} 7 \mathrm{ra02040f}$

rsc.li/rsc-advances

\section{A fluorescent and colorimetric sensor based on
a porphyrin doped polystyrene nanoporous fiber \\ A fluorescent and colorimetric sensor based on
a porphyrin doped polystyrene nanoporous fiber membrane for $\mathrm{HCl}$ gas detection $\dagger$}

\begin{abstract}
A facile fluorescent and colorimetric sensor capable of naked-eye detection of gaseous hydrogen chloride $(\mathrm{HCl})$ was developed. This technology uses the optical probe 5,10,15,20-tetraphenylporphyrin immobilized in a polystyrene nanoporous fiber membrane ( $\mathrm{TPPH}_{2}$-PS NFM) which was fabricated by electrospinning. The surface morphology and porous structures of the $\mathrm{TPPH}_{2}-\mathrm{PS}$ NFM were characterized and $\mathrm{HCl}$ gas sensing properties of the sensor was monitored by fluorescence spectrophotometry. Exposure to $\mathrm{HCl}$ gas causes apparent color change of the sensor from pink to yellow-green. The sample of THF-40 showed the maximum pseudo-second-order rate constant due to its largest specific surface area and pore volume. The detection limit was found to be $46 \mathrm{ppb}$ and the response time was $5 \mathrm{~s}$. The sensor exhibits excellent reversibility and prompt response and recovery which shed light on developing lowcost $\mathrm{HCl}$ gas sensing systems.
\end{abstract} Min Hu, (D) ${ }^{a}$ Weimin Kang, ${ }^{\text {ab }}$ Yixia Zhao, ${ }^{b}$ Jie Shi ${ }^{a}$ and Bowen Cheng (iD) *ab

\section{Introduction}

Fluorescent and colorimetric sensors have emerged as a powerful new approach toward the detection of gaseous pollutants at ppm or ppb concentration levels. ${ }^{1-4}$ In contrast to other detecting approaches, fluorescent and colorimetric sensors present a number of advantages, such as instrumental simplicity, low-cost, high sensitivity, fast response, good reversibility, permit real-time analyses, etc. ${ }^{5}$ Monitoring of gaseous pollutants is very important because the quality of the atmospheric environment is directly relevant for human health and life. $\mathrm{HCl}$ gas is one of the toxic gases which is mainly derived from complete burning of halogenated polymers, incineration of plants and absorbing towers of semiconductor factories and is strictly regulated in many countries now. ${ }^{6-8}$ The threshold for tolerably safe exposure to $\mathrm{HCl}$ gas is $10 \mathrm{ppm}$ and the exposure limit of $5 \mathrm{ppm}$ has been identified as a work place hazard. ${ }^{9,10}$ For this reason, a reliably fluorescent and colorimetric sensor for $\mathrm{HCl}$ gas detection is strongly demanded.

Hitherto, the centerpiece of most fluorescent and colorimetric sensors is the fluorescent sensing materials. ${ }^{11-13}$ Porphyrin is a common organic dye and has attracted much interest as the fluorescent sensing materials for toxic gas

${ }^{a}$ School of Textile, Tianjin Polytechnic University, Tianjin 300387, PR China. E-mail: kweimin@126.com; bowen15@tjpu.edu.cn

${ }^{b}$ Key Laboratory of Separation Membranes and Membrane Processes, Tianjin 300387, PR China

$\dagger$ Electronic supplementary information (ESI) available: FESEM images of the $\mathrm{TPPH}_{2}$-PS NFMs with different $\mathrm{TPPH}_{2}$ content and the thermostability of the $\mathrm{TPPH}_{2}-\mathrm{PS}$ NFM. See DOI: $10.1039 / \mathrm{c} 7 \mathrm{ra02040f}$ detection due to its highly conjugated $\pi$-electron structure, distinctive fluorescence bands in the visible region as well as selectivity of the designated gas. ${ }^{14-16}$ Most of these porphyrinbased optochemical sensors mainly incorporate porphyrin into glasses, sol-gel, solid state films, etc. ${ }^{17-22}$ It is well known that the efficiency of these gas sensor is greatly dependent on the structure of the sensing materials. ${ }^{11}$ Due to its large specific surface area, high porosity and excellent accessibility for gaseous analytes, porous structure is highly attractive to the sensing materials. For example, F. W. Lin et al. ${ }^{23}$ fabricated honeycomb-patterned porous films for sensing of hazardous $\mathrm{HCl}$ gas. The well-ordered porous films sensor shows remarkable fluorescence quenching behavior toward $\mathrm{HCl}$ gas with quenching ratios of $72 \%$ higher than that of the corresponding dense film. Y.-Y. Lv et al. ${ }^{24}$ prepared a nanofibrous membrane of porphyrinated polyimide for the rapid detection of $\mathrm{HCl}$ gas. The fluorescence quenching of nanofibrous membrane is much significant than that of dense film due to its three dimensional and porous structures, and hence good gas accessibility.

Recently, electrospinning is one of the most promising approaches to fabricate nanofibers with nano- and micro-porous structure. ${ }^{25-27}$ Polystyrene (PS), a common thermoplastic polymer with low surface energy, has been widely used to fabricate porous nanofibers via directly electrospinning method. ${ }^{28,29}$ Owing to its low toxicity, cheaper cost and excellent photostability, PS has become the most popular smart material to envelop sensitive probes for oxygen measurement. ${ }^{30}$ However, to the best of our knowledge, there have been few studies regarding PS nanoporous fibers for the detection of $\mathrm{HCl}$ gas. ${ }^{13,31-33}$

In this work, we successfully demonstrated that $\mathrm{TPPH}_{2}-\mathrm{PS}$ NFM can be used for the naked-eye detection of $\mathrm{HCl}$ gas at ppm- 
level based on a simple color change. The PS nanoporous fiber membrane was prepared by electrospinning and $\mathrm{TPPH}_{2}$ was immobilized in the PS NFM uniformly. Furthermore, $\mathrm{HCl}$ gas sensing properties of the $\mathrm{TPPH}_{2}$-PS NFM sensor was monitored via distinct fluorescence variation.

\section{Experimental}

\section{Materials}

Polystyrene (PS) with molecular weight of $M_{\mathrm{w}}=208000 \mathrm{~g} \mathrm{~mol} \mathrm{~m}^{-1}$ was provided by Wako, Japan. 5,10,15,20-Tetraphenylporphyrin $\left(\mathrm{TPPH}_{2}\right)$ (reagent grade, 97\%) was purchased from J\&K Technology Co., China. Tetrahydrofuran (THF) and $\mathrm{N}, \mathrm{N}$-dimethylformamide (DMF) were obtained from Tianjin Fengchuan Chemical Reagent Co., Ltd., China.

\section{Preparation of the TPPH $_{2}$-PS NFM}

PS and $\mathrm{TPPH}_{2}$ were dissolved in THF : DMF mixtures to obtain the electrospinning solutions. The concentration of PS, $\mathrm{TPPH}_{2}$ contents and weight ratios of THF : DMF mixtures were listed in Table 1. All the chemical reagents were used without further purification. Then the spinning solution was placed in a syringe and was pumped through a metal capillary with an inner diameter of $0.8 \mathrm{~mm}$ by a syringe pump (WZL-506, Smiths Medical Instrument Zhejiang Co., Ltd., China). The solution feeding rate was controlled at $1.0 \mathrm{~mL} \mathrm{~h}^{-1}$. A high voltage power supply (DW-P303-1ACD8, Tianjin Dongwen High Voltage Co., China) was used to generate a potential difference of $20 \mathrm{kV}$ between the capillary and an aluminum foil covered grounded metallic rotating roller rotated at $280 \mathrm{rpm}$. The work distance (WD) was kept at $20 \mathrm{~cm}$. All the experiments were carried out at $25^{\circ} \mathrm{C}$ and the relative humidity $(\mathrm{RH})$ was $50 \pm 2 \%$. The spinning time was fixed in $5 \mathrm{~h}$ so that the thickness of $\mathrm{TPPH}_{2}$-PS NFMs was $0.11 \pm 0.005 \mathrm{~mm}$. After electrospinning the $\mathrm{TPPH}_{2}$-PS NFMs were dried in vacuum at $40{ }^{\circ} \mathrm{C}$ for $24 \mathrm{~h}$.

\section{Characterization}

The morphology and cross-section of the electrospun $\mathrm{TPPH}_{2}$-PS NFMs was observed by field emission scanning electron microscope (FE-SEM) (S-4800, Hitachi, Japan) at an acceleration voltage of $5 \mathrm{kV}$ and high vacuum mode after gold coating. The

Table 1 Formulas of the $\mathrm{TPPH}_{2}$-PS electrospinning solutions

\begin{tabular}{lllll}
\hline & $\begin{array}{l}\text { PS } \\
\text { concentration } \\
(\text { wt\% })\end{array}$ & $\begin{array}{l}\mathrm{TPPH}_{2} \\
\text { content } \\
\left(\mathrm{mg} \mathrm{mL}^{-1}\right)\end{array}$ & $\mathrm{m}(\mathrm{THF}): \mathrm{m}(\mathrm{DMF})$ & $\begin{array}{l}\mathrm{TPPH}_{2} / \mathrm{PS} \\
\left(\mathrm{g} \mathrm{g}^{-1}\right)\end{array}$ \\
\hline THF-0 & 25 & 2.0 & $0: 100$ & 0.0063 \\
THF-20 & 25 & 2.0 & $20: 80$ & 0.0064 \\
THF-40 & 25 & 2.0 & $40: 60$ & 0.0067 \\
$\mathrm{THF}^{-60}$ & 25 & 2.0 & $60: 40$ & 0.0066 \\
$\mathrm{TPPH}_{2}-1.0$ & 25 & 1.0 & $40: 60$ & 0.0033 \\
$\mathrm{TPPH}_{2}-1.5$ & 25 & 1.5 & $40: 60$ & 0.0050 \\
$\mathrm{TPPH}_{2}-2.0$ & 25 & 2.0 & $40: 60$ & 0.0067 \\
$\mathrm{TPPH}_{2}-2.5$ & 25 & 2.5 & $40: 60$ & 0.0083
\end{tabular}

average fiber diameter of each sample was measured by image analysis software (Image Pro Plus 6.0). Fluorescent images of the samples were captured on fluorescence microscope (Nikon $\mathrm{A1}^{+}$, Nikon, Japan). The wavelength of excitation was $488 \mathrm{~nm} . \mathrm{N}_{2}$ adsorption-desorption data were measured using a specific surface and micropore analyzer (Autosorb-iQ, Quantachrome, USA). The specific surface area of the $\mathrm{TPPH}_{2}$-PS NFM was obtained from the $\mathrm{N}_{2}$ adsorption data in the relative pressure range from 0.05 to 0.3 by using the Brunauer-Emmett-Teller (BET) method. The total pore volume, pore size and its distribution of the fiber membrane were calculated by the BarrettJoyner-Halenda (BJH) method. The thermogravimetric (TG) analysis was performed using a thermal analyzer (STA 409 PC/ PG, Netzsch, Germany), under nitrogen flow, in a temperature range from $20^{\circ} \mathrm{C}$ to $800{ }^{\circ} \mathrm{C}$ and at a heating rate of $10^{\circ} \mathrm{C} \mathrm{min}{ }^{-1}$. UV-vis absorbance spectra of the $\mathrm{TPPH}_{2}$-PS NFMs were measured by UV-Visible spectrophotometer (EVOLUTION 220, Thermo, USA) which is assembly attached to the ISA-220 integrating sphere. The Czerny-Turner monochromator (Thermo, USA) was used and the acquisition time was 2 min. Fluorescence emission spectra were conducted on fluorescence spectrophotometer (F-380, Gangdong Sci., China) with a solid assembly to have excitation and emission at $45^{\circ}$ to the membrane surface. Samples were excited at $420 \mathrm{~nm}$ and emission was measured at wavelength of 600-760 $\mathrm{nm}$. Water contact angle measurements were performed with contact angle instrument (JYSP-180, Jinshengxin, China) using the static sessile drop method with DROP image advanced software to determine static contact angles.

\section{HCl gas sensing setup}

Sensor samples were prepared by cutting the $\mathrm{TPPH}_{2}$-PS NFMs into round shape (the diameter is about $1 \mathrm{~cm}$ ). $\mathrm{HCl}$ gas detection was carried out in a specially designed gas testing chamber comprising two high precision mass flow controllers (red-y, Voegtlin, Germany) which delivered a mixture of $\mathrm{HCl}$ gas and pure $\mathrm{N}_{2}$ to obtain required $\mathrm{HCl}$ gas concentration. The volume of the gas testing chamber was $1 \mathrm{~L}$. The $\mathrm{HCl}$ gas was detected at $40{ }^{\circ} \mathrm{C}$ in $50 \pm 2 \% \mathrm{RH}$. The fluorescence intensity at $645 \mathrm{~nm}$ of the sensor $\left(I_{0}\right.$ and $I$ ) before and after $\mathrm{HCl}$ gas exposure were recorded by the fluorescence spectrophotometer. After each exposure, the chamber was flushed with pure nitrogen to recover the $\mathrm{TPPH}_{2}$-PS NFM until the fluorescence intensity at $645 \mathrm{~nm}$ of the sensor approximate the original $I_{0}$. Visible color variation of the sensor when exposed to $\mathrm{HCl}$ gas was recorded by a digital camera (IXUS 210, Canon, Japan) in the same condition to ensure the accuracy of these color pictures.

\section{Results and discussion}

\section{Characterization of the TPPH $_{2}$-PS NFM}

Fig. 1 shows the FE-SEM images of $\mathrm{TPPH}_{2}$-PS NFMs from $\mathrm{TPPH}_{2}$-PS solutions of various solvent compositions via electrospinning method. Nonporous and bead-on-string structure was obtained from only DMF solvent due to the high boiling point of DMF $\left(153^{\circ} \mathrm{C}\right)$ which was incompletely evaporated 


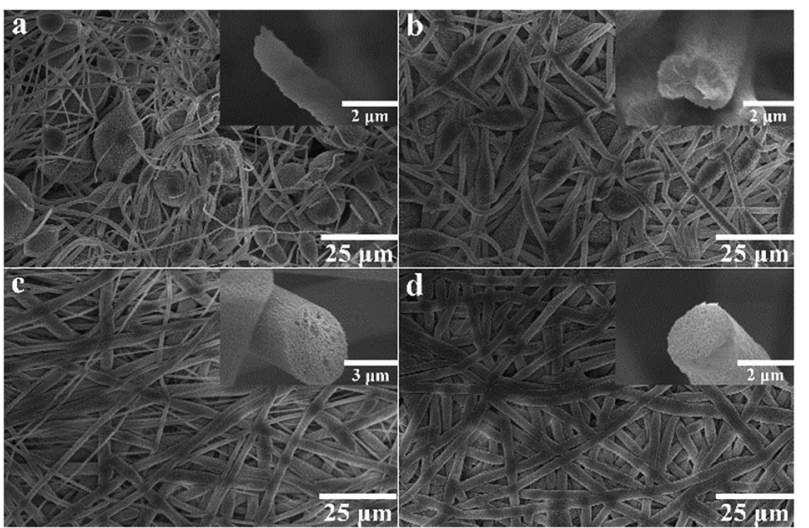

Fig. 1 FE-SEM images of the TPPH $\mathrm{H}_{2}$-PS NFMs formed from various weight ratios of THF : DMF in solvent: (a) $0: 100$, (b) $20: 80$, (c) $40: 60$, (d) $60: 40$, respectively. The inset images were the crosssection of $\mathrm{TPPH}_{2}$-PS fibers.

before the fibers were collected at the collector (Fig. 1a). With the increase of the low boiling point of THF $\left(66^{\circ} \mathrm{C}\right)$, the amount of bead-on-string structure decreased and disappeared when the ratio of THF was up to $40 \%$. It can be seen that the fiber comprised a grooved sheath and a solid core when a solvent mixture with $20 \%$ THF was used (insets of Fig. 1b). With the increasing THF percentage in the solvent mixtures, the nanopores presented on the fiber surfaces, and the porous structure appeared to be throughout the cross-sections of these fibers (insets of Fig. 1c). As the THF content further increased, the 3D interconnected nanopores inside the fibers became more uniform and dense as shown in insets of Fig. 1d. The morphology of the $\mathrm{TPPH}_{2}$-PS NFMs with different $\mathrm{TPPH}_{2}$ content is shown in Fig. S1. $\dagger$ The $\mathrm{TPPH}_{2}$ content has little impact on the fiber preparation and pore formation and the fiber diameter is in range of $800-3000 \mathrm{~nm}$. Fluorescent images of the $\mathrm{TPPH}_{2}-\mathrm{PS}$ NFM are shown in Fig. 2. Clearly, the TPPH $\mathrm{T}_{2}$-PS NFM shows uniform red fluorescence, while the pure PS NFM

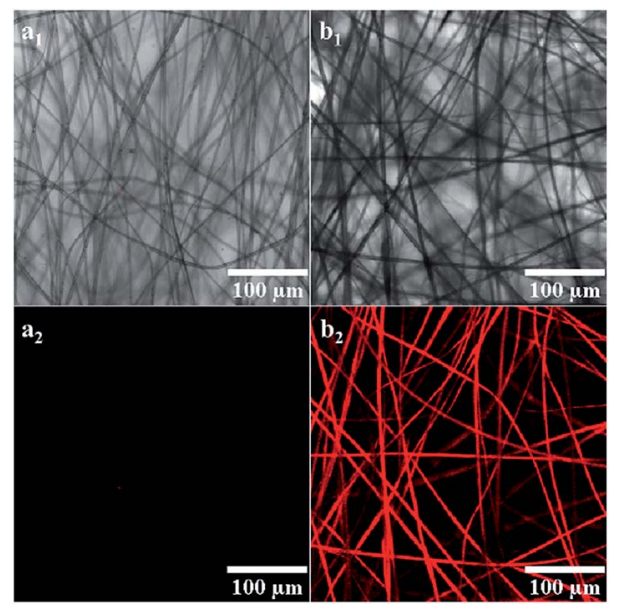

Fig. 2 Fluorescent images of the sample THF-40 with different $\mathrm{TPPH}_{2}$ content: (a) $0 \mathrm{mg} \mathrm{mL}^{-1}$, (b) $2.0 \mathrm{mg} \mathrm{mL}^{-1}\left(a_{1}, b_{1}\right.$-bright-field image, $a_{2}$, $b_{2}$-fluorescent image) $\left(\lambda_{e x}=488 \mathrm{~nm}\right)$. without $\mathrm{TPPH}_{2}$ doped shows none fluorescence. It confirms that $\mathrm{TPPH}_{2}$ is homogeneously dispersed in the surface and inside of the nanoporous PS fiber membrane.

The main reasons for pores formation of the fibers have been proved to be the thermally-induced phase separation and vaporinduced phase separation by previous studies. ${ }^{29,34}$ During electrospinning, the solvent evaporated from the polymer fluid jets involves the flash vaporization at the fiber surface and the diffusion from core to surface. In the meantime, moisture in the air will penetrate into the fluid jet while the solvent will diffuse out from the core of the jet. This is accompanied by cooling the fluid jets, leading to thermodynamically unstable jets and phase separation into polymer-rich and solvent-rich domains. ${ }^{31}$ Eventually, the polymer-rich phase solidified into fiber matrix and the solvent-rich phase transformed into nanopores as the solvent diffused out. The difference in the porous structure of these fibers can be attributed to the competition between the rapid phase separation and solidification resulting from the mutual diffusion of the solvent within the jet and the surrounding moisture due to the different solvent compositions of THF and DMF utilized in electrospinning.

Fig. 3 presents the nitrogen adsorption-desorption isotherms and pore size distribution curves of the $\mathrm{TPPH}_{2}$-PS NFMs formed with various ratios of THF-DMF. The isotherms of THF- 0 and THF- 20 are in accordance with the type III isotherm which is characteristic of macropores, while the isotherms of THF- 40 and THF- 60 are akin to a type II isotherm with a hysteresis loop which is the characteristics of mesopores and macropores according to the International Union and Applied Chemistry (IUPAC) classification. ${ }^{34,35}$ The inset of Fig. 3 reveals that the pore size is in the range of $2-60 \mathrm{~nm}$. Such porous structures are expected to contribute to higher specific surface area of these $\mathrm{TPPH}_{2}$-PS NFMs. The specific surface area and pore volume derived from BET measurements as well as average fiber diameter of the $\mathrm{TPPH}_{2}$-PS NFMs formed with various ratios of THF-DMF are show in Table 2. It is obvious that the varied solvent compositions exhibit the significant effects. THF-40 has the highest specific surface area of $58.63 \mathrm{~m}^{2}$

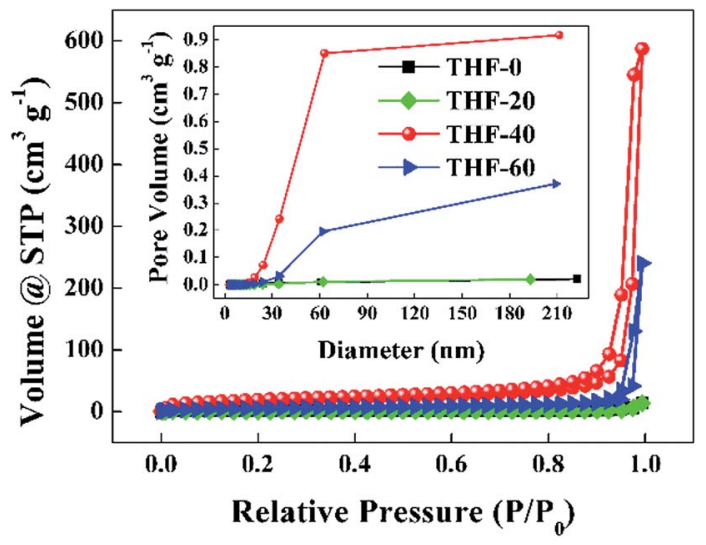

Fig. 3 Nitrogen adsorption-desorption isotherms and pore size distribution curves (inset) of the $\mathrm{TPPH}_{2}$-PS NFMs formed with various ratios of THF-DMF. 
Table 2 The specific surface area, pore volume and average fiber diameter of the $\mathrm{TPPH}_{2}$-PS NFMs formed with various ratios of THFDMF

\begin{tabular}{llll}
\hline Sample & $\begin{array}{l}\text { Specific surface } \\
\text { area }\left(\mathrm{m}^{2} \mathrm{~g}^{-1}\right)\end{array}$ & $\begin{array}{l}\text { Pore volume } \\
\left(\mathrm{cm}^{3} \mathrm{~g}^{-1}\right)\end{array}$ & $\begin{array}{l}\text { Average fiber } \\
\text { diameter }(\mathrm{nm})\end{array}$ \\
\hline THF-0 & 2.52 & 0.009 & 951 \\
THF-20 & 2.27 & 0.008 & 1933 \\
THF-40 & 58.63 & 0.851 & 1609 \\
THF-60 & 17.81 & 0.195 & 2807
\end{tabular}

$\mathrm{g}^{-1}$, the biggest pore volume of $0.851 \mathrm{~cm}^{3} \mathrm{~g}^{-1}$ and the smallest average fiber diameter of $1609 \mathrm{~nm}$. As the low boiling point of THF content increased, the average fiber diameter of THF-60 increased while the its pore volume decreased due to the faster speed on solidification of the electrospinning jet, result to lower specific surface area. THF-0 and THF-20 have the lowest specific surface area and pore volume because of their poor porous structure in spite of their fiber diameters are small. In addition, the weight loss of the $\mathrm{TPPH}_{2}$-PS NFM happens at approximately $400{ }^{\circ} \mathrm{C}$, which confirm its good thermostability used as $\mathrm{HCl}$ gas sensor (Fig. S2 $\dagger$ ).

\section{HCl gas sensing properties of the TPPH $_{2}-\mathrm{PS}$ NFM}

The detection of $\mathrm{HCl}$ gas was carried out to study the sensing properties of the as-prepared $\mathrm{TPPH}_{2}$-PS NFM sensor. $\mathrm{HCl}$ gas of certain concentration was introduced to the test chamber where the sensor was placed. The sensor samples were prepared in the same size, which the diameter is about $1 \mathrm{~cm}$ and the thickness is about $0.11 \mathrm{~mm}$. The $\mathrm{HCl}$ gas exposure test was carried out at $40{ }^{\circ} \mathrm{C}$ in $50 \pm 2 \% \mathrm{RH}$. As shown in Fig. 4, the sensor presents a visible color variation from pink to yellow green with a concentration of $\mathrm{HCl}$ gas up to $1000 \mathrm{ppm}$. When repeatedly flushing the protonated $\mathrm{TPPH}_{2}$-PS NFM sensor with pure $\mathrm{N}_{2}$ three times for $1 \mathrm{~min}$, the color of the sensor is completely reverted back to its original state. This vivid color variation can be ascribed to the reversible protonation reaction between $\mathrm{H}^{+}$of $\mathrm{HCl}$ and the central nitrogen of the $\mathrm{TPPH}_{2}$ molecule. ${ }^{17,36}$ Initially, $\mathrm{TPPH}_{2}$ molecule has a planar structure with all phenyl group perpendicular to the plane of the porphyrin ring. After protonated with $\mathrm{HCl}$ gas, the planarity of the porphyrin ring is destroyed and change to saddle conformation resulting to the obvious color variation of the sensor. ${ }^{\mathbf{1 0 , 3 7}}$ Considering the threshold for tolerably safe exposure to $\mathrm{HCl}$ gas (10 ppm) and the exposure limit in work place $(5 \mathrm{ppm})$, the as-prepared $\mathrm{TPPH}_{2}$-PS NFM sensor could be used to briefly evaluate the concentration of $\mathrm{HCl}$ gas ranging from $1 \mathrm{ppm}$ to $60 \mathrm{ppm}$

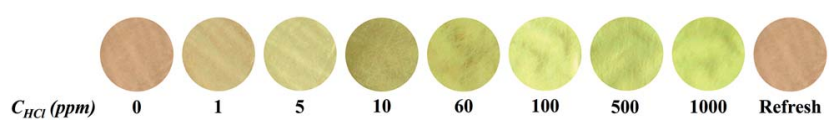

Fig. 4 Color pictures of the sample THF-40 exposed to different concentrations of $\mathrm{HCl}$ gas $\left(\mathrm{C}_{\mathrm{HCl}}\right)$ for $30 \mathrm{~s}$ at $40{ }^{\circ} \mathrm{C}$ in $50 \pm 2 \% \mathrm{RH}$ and refreshed by $\mathrm{N}_{2}$. without resorting to the use of expensive instruments which is necessary for developing low-cost $\mathrm{HCl}$ gas sensing systems.

UV-visible absorption spectra of the $\mathrm{TPPH}_{2}$-PS NFM exposed to 0-1000 ppm $\mathrm{HCl}$ gas are shown in Fig. 5a. It displays a distinctive Soret band around $420 \mathrm{~nm}$ and four weaker Q bands at 518, 552, 593 and $650 \mathrm{~nm}$ before $\mathrm{HCl}$ gas exposure. The Soret band features a gradual bathochromic shift of $22 \mathrm{~nm}$, from 420 to $442 \mathrm{~nm}$ upon the addition of $\mathrm{HCl}$ gas exposed to the $\mathrm{TPPH}_{2}$-PS NFM, which is consistent with the research result of Y.-Y. Lv et al. ${ }^{24}$ Also the Q band at $650 \mathrm{~nm}$ becomes stronger as the concentration of $\mathrm{HCl}$ gas increases. These spectral changes are attributed to the protonation reaction between $\mathrm{H}^{+}$and the central nitrogen of the $\mathrm{TPPH}_{2}$, which causes the charge-transfer complex between $\mathrm{H}^{+}$and $\mathrm{TPPH}_{2}$, and hence the visible color variation of the $\mathrm{TPPH}_{2}$-PS NFM. ${ }^{38}$ As shown in Fig. 5b, fluorescence quenching is also obvious and the intensities of emission spectra at $645 \mathrm{~nm}$ and $710 \mathrm{~nm}$ decrease with the increased concentration of $\mathrm{HCl}$ gas which is another proof of the protonation on $\mathrm{TPPH}_{2}$. When the sensor is refreshed by $\mathrm{N}_{2}$, the absorption and emission spectra of the $\mathrm{TPPH}_{2}-\mathrm{PS}$ NFM return to nearly the original states shown by the dash line of Fig. 5 which confirms the deprotonation of the $\mathrm{TPPH}_{2}$ resulting the color recovery of the sensor.

For further study of the sensing response of $\mathrm{TPPH}_{2}$-PS NFM sensor, fluorescence spectra of the sensor exposed to $\mathrm{HCl}$ gas with concentration of 0-3000 ppm were measured. The sensing response were calculated from specific value of the intensity at $645 \mathrm{~nm}\left(I_{0} / I\right)$. Fig. S $3 \uparrow$ shows the sensing response of the sample
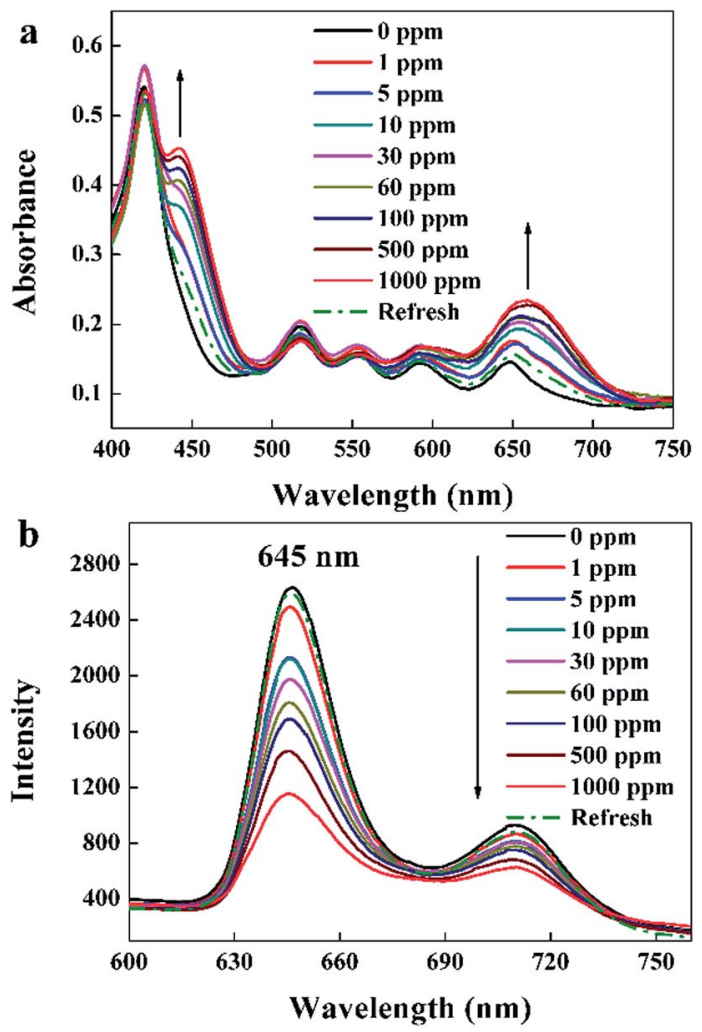

Fig. 5 UV-visible absorption spectra (a) and fluorescence spectra (b, $\lambda_{\text {ex }}=420 \mathrm{~nm}$ ) of the sample THF-40 exposure to different concentrations of $\mathrm{HCl}$ gas for $30 \mathrm{~s}$ at $40{ }^{\circ} \mathrm{C}$ in $50 \pm 2 \% \mathrm{RH}$ and refreshed by $\mathrm{N}_{2}$. 
THF-40 exposure to different concentration of $\mathrm{HCl}$ gas. The slope of the curve presents a linear increase at lower $\mathrm{HCl}$ concentration range in $0-5 \mathrm{ppm}$. At higher concentrations, the concentration dependence conform to non-linear due to the saturation effects. ${ }^{39}$ As shown in Fig. 6, a linear fitting is used to fit the value of $I_{0} / I$ at $645 \mathrm{~nm}$ against the concentration of $\mathrm{HCl}$ gas ranging from $0 \mathrm{ppm}$ to $5 \mathrm{ppm}$, which can be described by the Stern-Volmer eqn (1). ${ }^{40}$

$$
\frac{I_{0}}{I}=1+K_{\mathrm{SV}}[\mathrm{Q}]
$$

where $I_{0}$ and $I$ represented the fluorescence intensity at $645 \mathrm{~nm}$ of the sensor before and after exposure to $\mathrm{HCl}$ gas for $30 \mathrm{~s}$ at $40{ }^{\circ} \mathrm{C}$, respectively. [Q] is the concentration of $\mathrm{HCl}$ gas and $K_{\mathrm{SV}}$ is the Stern-Volmer quenching constant. The detection limit (DL) of the sensor was computed as the eqn (2). ${ }^{39,41}$

$$
\mathrm{DL}=\frac{3 \sigma}{S}
$$

where $\sigma$ is the standard deviation of the blank signal $(n=6)$ and $S$ is the slope of the linear calibration plot. The DL of the $\mathrm{TPPH}_{2}$ PS NFM sensor toward $\mathrm{HCl}$ gas was found to be $46 \mathrm{ppb}$.

Fast response is a significant requirement to be considered for gas sensor. Fig. $\mathrm{S} 4 \uparrow$ shows the exposure time dependence of $I_{0} / I$ at $645 \mathrm{~nm}$ after the sensor exposed to $100 \mathrm{ppm} \mathrm{HCl}$ gas. The slope of all the curves presents a linear increase at the initial region and turns to equilibrium after $5 \mathrm{~s}$. However, the response time of compact films, such as composite film ${ }^{42}$ and LS film, ${ }^{38}$ based gas sensors is in several minutes which indicates that the structure of these sensing films is the major factor influencing the response time of the gas sensor. Kinetic data were fitted based on the linear region of the curves shown in Fig. $\mathrm{S} 4 \uparrow$ using kinetic models to assess the $\mathrm{HCl}$ gas adsorption of the $\mathrm{TPPH}_{2}-\mathrm{PS}$ NFM with different structure and $\mathrm{TPPH}_{2}$ content. According to eqn (1), the linear equation of pseudo-first-order and pseudosecond-order kinetics can be deformed to eqn (3) and (4). ${ }^{43-46}$

$$
\begin{aligned}
& \log \frac{I_{0}}{I}=k_{1} t \\
& \frac{1}{I}=k_{2} t+\frac{1}{I_{0}}
\end{aligned}
$$

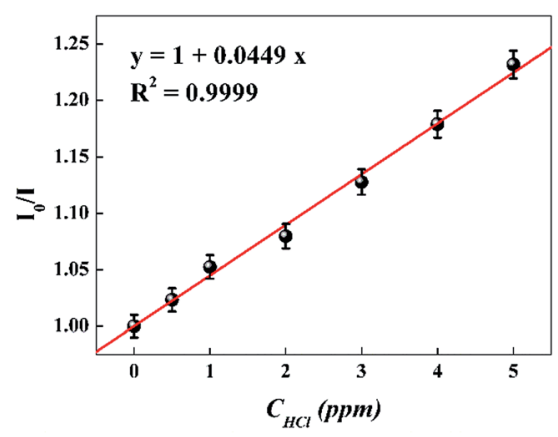

Fig. 6 Stern-Volmer plot of the sensor. $I_{0}$ and I represented the fluorescence intensity of the sensor before and after exposure to $\mathrm{HCl}$ gas, respectively. ( $\lambda_{\mathrm{ex}}=420 \mathrm{~nm}, \lambda_{\mathrm{em}}=645 \mathrm{~nm}$ ). where $I_{0}$ and $I$ represented the fluorescence intensity at $645 \mathrm{~nm}$ of the sensor before and after exposure to $100 \mathrm{ppm} \mathrm{HCl}$ gas for $t \mathrm{~s}$ at $40{ }^{\circ} \mathrm{C}$, respectively. $k_{1}$ and $k_{2}$ are the pseudo-first-order and pseudo-second-order rate constant. As illustrated in Table 2, the porous structure of the $\mathrm{TPPH}_{2}$-PS NFM is relevant to the solvent compositions. Therefore, kinetic fitting of the $\mathrm{TPPH}_{2}$-PS NFMs with various ratios of THF-DMF was shown in Fig. 7a to investigate the effect of porous structure on $\mathrm{HCl}$ gas adsorption. The kinetic parameters is shown in Table 3.

It is clearly indicate that the pseudo-second-order model fit the kinetic data well, with $R^{2}$ over 0.99 . The sample of THF-40 has the maximum $k_{2}$ of $5.67 \times 10^{-5}$ which confirm that high specific surface area and pore volume is suitable for gas adsorption and diffusion. Fig. 7b shows kinetic fitting of the $\mathrm{TPPH}_{2}$-PS NFMs with different $\mathrm{TPPH}_{2}$ content and the kinetic parameters of the effect of $\mathrm{TPPH}_{2}$ content on $\mathrm{HCl}$ gas adsorption is also shown in Table 3. With the increase of the $\mathrm{TPPH}_{2}$ content, the value of $k_{2}$ increases and reaches the peak with $\mathrm{TPPH}_{2}$ content up to $2.0 \mathrm{mg} \mathrm{mL}{ }^{-1}$. As the $\mathrm{TPPH}_{2}$ content further increased, the value of $k_{2}$ decreases because a large proportion of the porphyrin results in some porphyrin crystals. ${ }^{42}$

\section{Reversibility, photostability and humidity insensitivity of the sensor}

When the sensor is continuously monitored in rapidly alternated gaseous atmospheres, the specific value of $I_{0} / I$ at $645 \mathrm{~nm}$ rise and recover with the environment switched between $100 \mathrm{ppm} \mathrm{HCl}$ gas and pure $\mathrm{N}_{2}$ (Fig. 8a). The sensor exhibits excellent reversibility and prompt response and recovery. The response time taken as the time required to reach $90 \%$ of the steady-state value is approximately $5 \mathrm{~s}$, and the recovery time taken as the time to recover the sensor to $10 \%$ of the span signal is approximately $90 \mathrm{~s}$. The photostability of this sensor was measured by recording $I_{0} / I$ at $645 \mathrm{~nm}$ per $12 \mathrm{~h}$ exposed to 100 ppm $\mathrm{HCl}$ gas and $\mathrm{N}_{2}$.
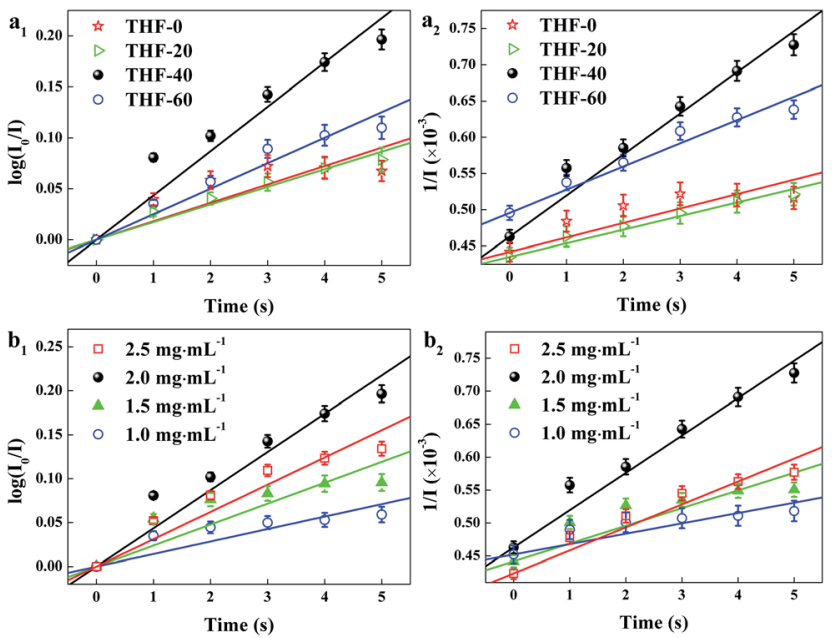

Fig. 7 Kinetic fitting of the $\mathrm{TPPH}_{2}$-PS NFMs with various ratios of THFDMF (a) and different TPPH $\mathrm{H}_{2}$ content (b) for the adsorption of $100 \mathrm{ppm}$ $\mathrm{HCl}$ gas for $0-5 \mathrm{~s}$. $\left(a_{1}, b_{1}\right)$ was pseudo-first-order and $\left(a_{2}, b_{2}\right)$ was pseudo-second-order kinetic fitting. 
Table 3 Kinetic parameters of the effect of porous structure and $\mathrm{TPPH}_{2}$ content on $\mathrm{HCl}$ gas adsorption

\begin{tabular}{llllll}
\hline & \multicolumn{2}{l}{$\begin{array}{l}\text { Pseudo-first-order } \\
\text { kinetics }\end{array}$} & & \multicolumn{2}{l}{$\begin{array}{l}\text { Pseudo-second-order } \\
\text { kinetics }\end{array}$} \\
\cline { 2 - 3 } Sample & $k_{1}\left(\times 10^{-2}\right)$ & $R_{1}{ }^{2}$ & & $k_{2}\left(\times 10^{-5}\right)$ & $R_{2}{ }^{2}$ \\
\hline THF-0 & 1.81 & 0.890 & & 2.00 & 0.998 \\
THF-20 & 1.73 & 0.985 & & 1.87 & 0.999 \\
THF-40 & 4.35 & 0.975 & & 5.67 & 0.999 \\
THF-60 & 2.51 & 0.980 & 3.21 & 0.999 \\
TPPH $_{2}-1.0$ & 1.42 & 0.911 & & 1.57 & 0.999 \\
TPPH $_{2}-1.5$ & 2.38 & 0.913 & 2.69 & 0.998 \\
TPPH $_{2}-2.0$ & 4.35 & 0.975 & 5.67 & 0.999 \\
TPPH $_{2}-2.5$ & 3.11 & 0.967 & 3.49 &
\end{tabular}

It can be seen that the sensing response of the sensor remains unchanged and the $\mathrm{TPPH}_{2}$-PLA NFM shows nearly no photobleaching (Fig. 8b). In this way, the sensor can be reused many times which is important in developing low-cost $\mathrm{HCl}$ gas sensing systems. As shown in Fig. 9, the RH conditions have nearly no effect on sensing response of the sensor exposed to $100 \mathrm{ppm} \mathrm{HCl}$ gas in $5 \mathrm{~s}$ due to the hydrophobicity of the $\mathrm{TPPH}_{2}-\mathrm{PS}$ NFM. The inset figure on the water contact angle of the $\mathrm{TPPH}_{2}$-PLA NFM in Fig. 9 confirms its excellent hydrophobicity.
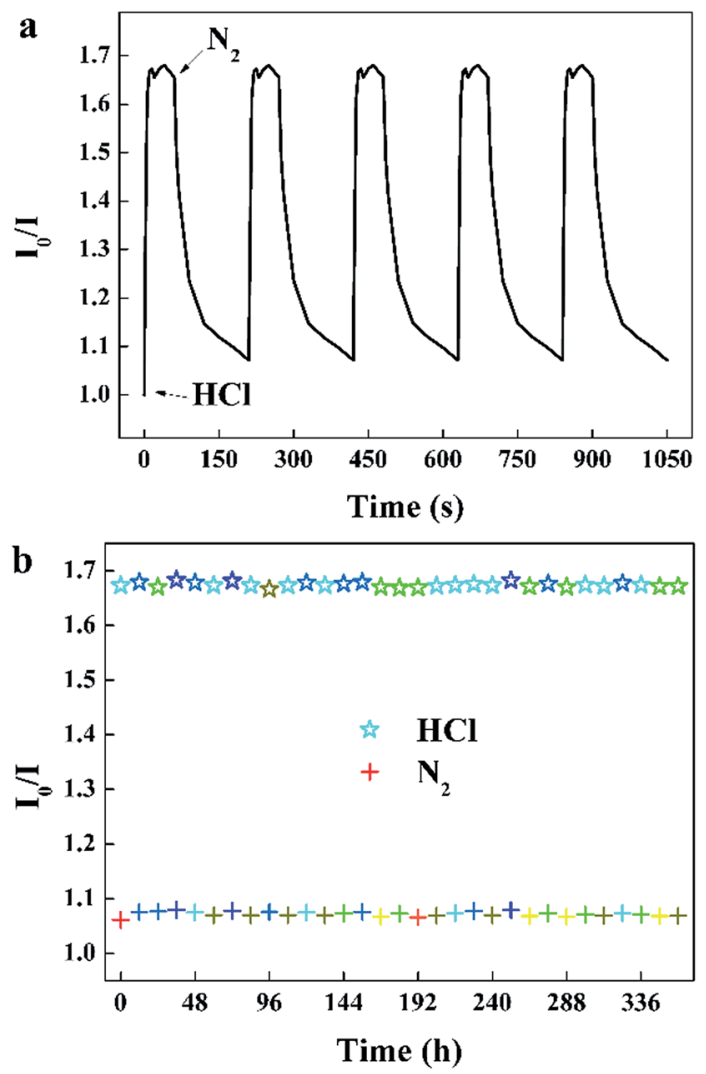

Fig. 8 (a) Reversibility of the sensor to alternating $100 \mathrm{ppm} \mathrm{HCl}$ gas and pure $\mathrm{N}_{2}$, (b) photostability of the sensor exposed to $100 \mathrm{ppm} \mathrm{HCl}$ gas and $N_{2}$ for $30 \mathrm{~s}$ per 12 hours $\left(\lambda_{\mathrm{em}}=645 \mathrm{~nm}\right)$.

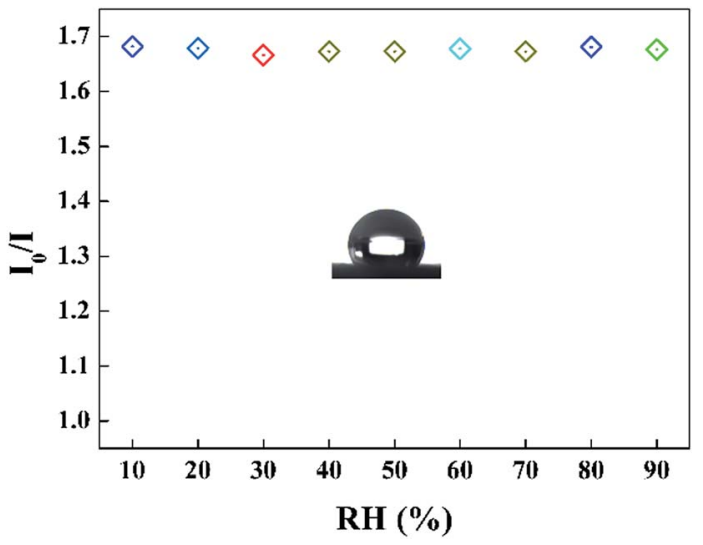

Fig. 9 Sensing response of the sensor in different $\mathrm{RH}$ conditions $\left(\lambda_{\mathrm{em}}\right.$ $=645 \mathrm{~nm}$ ) and the inset image presents the water contact angle of the $\mathrm{TPPH}_{2}$-PS NFM.

\section{Selectivity of the sensor}

To evaluate the selectivity of the proposed sensor, the sensing response $\left(I_{0} / I\right.$ at $\left.645 \mathrm{~nm}\right)$ is measured in the presence of various acid gases with the concentration of $100 \mathrm{ppm}$, such as gaseous $\mathrm{CO}_{2}, \mathrm{SO}_{2}, \mathrm{NO}, \mathrm{NO}_{2}$, etc. As shown in Fig. 10, a significant increase of $I_{0} / I$ at $645 \mathrm{~nm}$ could be observed when the sensor was exposed to $\mathrm{HCl}$ gas. By contrast, the value of $I_{0} / I$ at $645 \mathrm{~nm}$ presented little increase when the sensor exposure to $\mathrm{CO}_{2}, \mathrm{SO}_{2}$, $\mathrm{NO}, \mathrm{NO}_{2}$, respectively. As shown in the inset images of Fig. 10, the color of the sensor changed from pink to yellow green exposure to $\mathrm{HCl}$ gas, while remained unchanged exposure to other gaseous analytes of the test.

\section{Comparison with other $\mathrm{HCl}$ gas sensors based on porphyrin}

The comparison of some reported porphyrin based sensors for detection of $\mathrm{HCl}$ gas was show in Table 4. Compared to other conventional optical sensors of $\mathrm{HCl}$ gas based on porphyrin, this $\mathrm{TPPH}_{2}$-PS NFM sensor exhibits high sensitivity and fast response due to the large specific surface area, controllable pore sizes, well-defined porosity of the three dimensional

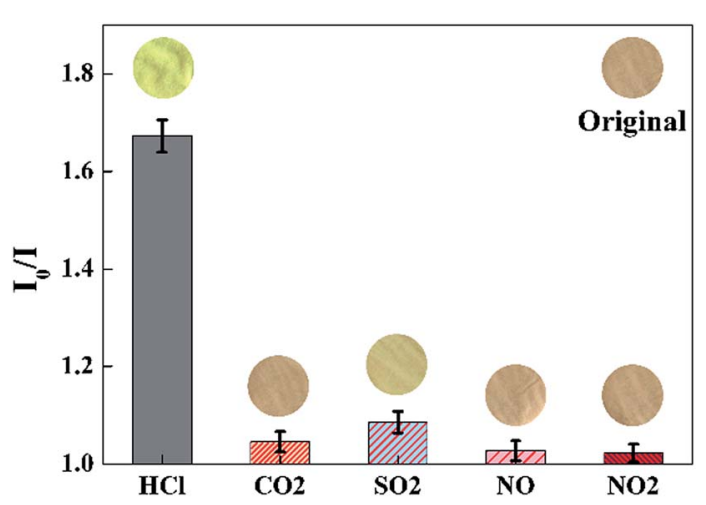

Fig. 10 Selectivity of the sensor exposed to other acid gases with the concentration of $100 \mathrm{ppm}$ for $30 \mathrm{~s}$ at $40{ }^{\circ} \mathrm{C}$ in $50 \pm 2 \% \mathrm{RH}$. Inset images were the color pictures of the sensor at each gaseous analytes. $\left(\lambda_{\mathrm{em}}=645 \mathrm{~nm}\right)$. 
Table 4 Comparison with other optical sensors for detection of $\mathrm{HCl}$ gas based on porphyrin

\begin{tabular}{|c|c|c|c|c|}
\hline Material & Method & $\mathrm{DL}(\mathrm{ppb})$ & Response time (s) & Ref. \\
\hline $\mathrm{TPPH}_{2}$-PS NFM & Fluorescence/colorimetric & 46 & 5 & This method \\
\hline $\mathrm{TMPyP} / \mathrm{TiO}_{2}$ composite thin film & Absorbance & 100 & $16.8 \pm 0.7$ & 47 \\
\hline MTMP deposited glass plate & Absorbance/fluorescence & 30 & $>180$ & 37 \\
\hline $\mathrm{TP}(\mathrm{OH})_{4} \mathrm{PH}_{2}$ dispersed MTEOS/TEOS sol-gel film & Reflectance & 500 & - & 18 \\
\hline Porphyrinated PI honeycomb film & Fluorescence & - & 10 & 23 \\
\hline
\end{tabular}

electrospun nanoporous fiber membrane and hence good accessibility for $\mathrm{HCl}$ gas. The sensor also presents good visual color change when exposure to $\mathrm{HCl}$ gas, which may be used for low-cost HCl sensor.

\section{Conclusions}

A fluorescent and colorimetric $\mathrm{HCl}$ gas sensor based on $\mathrm{TPPH}_{2}$ PS NFM was facilely fabricated by electrospinning for the nakedeye detection of $\mathrm{HCl}$ gas. The sensor presented apparent color change from pink to yellow green when exposed to ppm-level of $\mathrm{HCl}$ gas at $40{ }^{\circ} \mathrm{C}$. The sample of THF-40 showed very high sensitivity and the maximum pseudo-second-order rate constant of $5.67 \times 10^{-5}$ due to its largest specific surface area and pore volume. The detection limit was found to be $46 \mathrm{ppb}$ and the response time was $5 \mathrm{~s}$. The sensor also showed excellent reversibility and prompt response and recovery. As this colorimetric sensing approach is simple, low-coast, sensitive and prompt, the sensor foresees a high potential for the development of visual $\mathrm{HCl}$ gas sensor working in smart textiles.

\section{Acknowledgements}

This work was supported by National Natural Science Foundation of China (51102178), National Key Technology Support Program (2015BAE01B03) and Innovation Fund for Technology of Tianjin (14ZXCXGX00776).

\section{References}

1 H. N. Kim, W. X. Ren, J. S. Kim and J. Yoon, Chem. Soc. Rev., 2012, 41, 3210-3244.

2 G. De Luca, G. Pollicino, A. Romeo and L. M. Scolaro, Chem. Mater., 2006, 18, 2005-2007.

3 M. K. LaGasse, J. M. Rankin, J. R. Askim and K. S. Suslick, Sens. Actuators, B, 2014, 197, 116-122.

4 N. A. Rakow and K. S. Suslick, Nature, 2000, 406, 710-713.

5 J. Sun, B. Ye, G. Xia, X. Zhao and H. Wang, Sens. Actuators, B, 2016, 233, 76-82.

6 P. Kalimuthu, A. Sivanesan and S. A. John, J. Chem. Sci., 2012, 124, 1315-1325.

7 P. Muthukumar and S. A. John, Sens. Actuators, B, 2011, 159, 238-244.

8 Y. Itagaki, S. Yamanaka and Y. Sadaoka, Sens. Lett., 2011, 9, 114-117.
9 K. Nakagawa, K. Kumon, C. Tsutsumi, K. Tabuchi, T. Kitagawa and Y. Sadaoka, Sens. Actuators, B, 2000, 65, 138-140.

10 K. Nakagawa, Y. Sadaoka, H. Supriyatno, A. Kubo, C. Tsutsumi and K. Tabuchi, Sens. Actuators, B, 2001, 76, 42-46.

11 X. C. Sun, C. Bruckner, M. P. Nieh and Y. Lei, J. Mater. Chem. A, 2014, 2, 14613-14621.

12 B. P. Regmi, W. I. S. Galpothdeniya, N. Siraj, M. H. Webb, N. C. Speller and I. M. Warner, Sens. Actuators, B, 2015, 209, 172-179.

13 C. Wolf, M. Tscherner and S. Kostler, Sens. Actuators, B, 2015, 209, 1064-1069.

14 L. Maqueira, A. C. Valdés, A. Iribarren and C. P. de Melo, J. Porphyrins Phthalocyanines, 2013, 17, 283-288.

15 P. Castillero, J. R. Sanchez-Valencia, M. Cano, J. M. Pedrosa, J. Roales, A. Barranco and A. R. Gonzalez-Elipe, ACS Appl. Mater. Interfaces, 2010, 2, 712-721.

16 A. D. F. Dunbar, T. H. Richardson, J. Hutchinson and C. A. Hunter, Sens. Actuators, B, 2008, 128, 468-481.

17 Y. Itagaki, K. Deki, S.-I. Nakashima and Y. Sadaoka, Sens. Actuators, B, 2005, 108, 393-397.

18 Y. Itagaki, K. Deki, S.-I. Nakashima and Y. Sadaoka, Sens. Actuators, B, 2006, 117, 302-307.

19 J. Spadavecchia, G. Ciccarella, P. Siciliano, S. Capone and R. Rella, Sens. Actuators, B, 2004, 100, 88-93.

20 S. Jiang and M. Liu, Chem. Mater., 2004, 16, 3985-3987.

21 P. Muthukumar and S. A. John, Sens. Actuators, B, 2012, 174, 74-80.

22 K. Nakagawa, T. Aono, G. Ueda, C. Tsutsumi, N. Hayase, M. Mabuchi and Y. Sadaoka, Sens. Actuators, B, 2005, 108, 542-546.

23 F. W. Lin, X. L. Xu, L. S. Wan, J. Wu and Z. K. Xu, RSC Adv., 2015, 5, 30472-30477.

24 Y.-Y. Lv, J. Wu and Z.-K. Xu, Sens. Actuators, B, 2010, 148, 233-239.

25 J. Lin, Y. Shang, B. Ding, J. Yang, J. Yu and S. S. Al-Deyab, Mar. Pollut. Bull., 2012, 64, 347-352.

26 M. Bognitzki, W. Czado, T. Frese, A. Schaper, M. Hellwig, M. Steinhart, A. Greiner and J. H. Wendorff, Adv. Mater., 2001, 13, 70-72.

27 R. Gentsch, B. Boysen, A. Lankenau and H. G. Borner, Macromol. Rapid Commun., 2010, 31, 59-64.

28 H. Fashandi and M. Karimi, Polymer, 2012, 53, 5832-5849.

29 C. L. Casper, J. S. Stephens, N. G. Tassi, D. B. Chase and J. F. Rabolt, Macromolecules, 2004, 37, 573-578. 
30 S. Lu, W. Xu, Y. Chen, Y. Jiang, Q. Yao, F. Luo, Y. Wang and X. Chen, Sens. Actuators, B, 2016, 232, 585-594.

31 J. Y. Lin, B. Ding, J. M. Yang, J. Y. Yu and G. Sun, Nanoscale, 2012, 4, 176-182.

32 J. Lin, F. Tian, Y. Shang, F. Wang, B. Ding, J. Yu and Z. Guo, Nanoscale, 2013, 5, 2745-2755.

33 J. Huang, H. Deng, D. Song and H. Xu, Anal. Chim. Acta, 2015, 878, 102-108.

34 J. Lin, B. Ding, J. Yu and Y. Hsieh, ACS Appl. Mater. Interfaces, 2010, 2, 521-528.

35 K. S. W. Sing, D. H. Everett, R. A. W. Haul, L. Moscou, R. A. Pierotti, J. Rouquerol and T. Siemieniewska, Pure Appl. Chem., 1985, 57, 603.

36 M. Hu, W. Kang, B. Cheng, Z. Li, Y. Zhao and L. Li, Microchim. Acta, 2016, 183, 1713-1720.

37 P. Kalimuthu and S. Abraham John, Anal. Chim. Acta, 2008, 627, 247-253.

38 M. Evyapan and A. D. F. Dunbar, Sens. Actuators, B, 2015, 206, 74-83.
39 T. Balaji, M. Sasidharan and H. Matsunaga, Analyst, 2005, 130, 1162-1167.

40 T. W. Sung and Y. L. Lo, Sens. Actuators, B, 2013, 188, 702708.

41 T. H. Richardson, C. M. Dooling, L. T. Jones and R. A. Brook, Adv. Colloid Interface Sci., 2005, 116, 81-96.

42 K. Nakagawa, K. Tanaka, T. Kitagawa and Y. Sadaoka, J. Mater. Chem., 1998, 8, 1199-1204.

43 G. R. Fonda, J. Opt. Soc. Am., 1936, 26, 316-322.

44 S. Wei, J. Liu, S. Zhang, X. Chen, Q. Liu, L. Zhu, L. Guo and X. Liu, Hydrometallurgy, 2016, 164, 219-227.

45 L. J. Rather, I. Shahid ul, M. A. Khan and F. Mohammad, J. Environ. Chem. Eng., 2016, 4, 1780-1796.

46 W. Kang, X. Ma, M. Hu, Z. Jia, H. Liu and B. Cheng, Anal. Methods, 2016, 8, 6489-6493.

47 M. Cano, P. Castillero, J. Roales, J. M. Pedrosa, S. Brittle, T. Richardson, A. R. González-Elipe and A. Barranco, Sens. Actuators, B, 2010, 150, 764-769. 